\title{
A UNIVERSIDADE ABERTA À TERCEIRA IDADE (UATI) E A EXTENSÃO UNIVERSITÁRIA: RESSIGNIFICANDO A PRÁXIS ACADÊMICA NA UNEB CAMPUS XI - SERRINHA
}

\author{
Fernando de Souza Nunes \\ UNEB \\ fernandodsouzanunes@ hotmail.com
}

\begin{abstract}
Resumo
O aumento da expectativa de vida no Brasil, por meio do crescimento do número de idosos, requer mudanças no trato e na execução de políticas públicas do Estado devido a mudança no seu perfil. Visando subsidiar a promoção da dignidade humana dessa parcela da população, motivada por outras Instituições de Ensino Superior, a Universidade do Estado da Bahia (UNEB), criou a Universidade Aberta à Terceira Idade (UATI), presente na maioria dos seus Campi, em particular, na cidade de Serrinha, vinculada à Pró Reitoria de Extensão (PROEX) - daí a necessidade de ressignificar a extensão universitária como práxis acadêmica e sociopolítica por meio do referido programa. Através do método indutivo de cunho qualitativo, levantamento histórico/bibliográfico e revisão de literatura acerca das temáticas, pode-se inferir que a UATI é um programa/rede de extensão universitária em conformidade com as normas, planos, políticas nacionais e o estatuto do idoso, conforme as atividades desenvolvidas. Por fim, para melhor desempenhar as suas funções, é importante que haja maior apoio ao programa por parte do Governo do Estado da Bahia devido a relevância sociocultural a fim de melhorar a qualidade de vida dos idosos.
\end{abstract}

Palavras-chaves: Idosos. Extensão. Universidade. UATI.

\section{THE UNIVERSITY OPENS TO THE THIRD AGE (UATI) AND THE UNIVERSITY EXTENSION: REFRAINING THE ACADEMIC PRAXIS IN UNEB CAMPUS XI - SERRINHA}

\begin{abstract}
Abtract
The increase of the life expectancy in Brazil, by means of the growth of the number of aged, requires changes in the treatment and the execution of public politics of the State due the change in its profile. Aiming at to subsidize the promotion of the dignity human being of this parcel of the population, motivated for other Institutions of Superior Education, the University of the State of the Bahia (UNEB), it created the Open University to Third Age (UATI), gift in the majority of its campuses, in particular, the city of Serrinha, object of study of the present work, tied with the Dean of Extension (PROEX) - from there the necessity of reframe the extension college student as praxis academic and sociopolitical by means of the cited program. By means of the inductive method of qualitative matrix, bibliographical historical survey/and revision of literature concerning the thematic ones, can be inferred that the UATI is a program $/$ net of university extension in compliance with the norms, national plans, politics and the statute of the aged one, as the developed activities. Finally, better to play its functions, it is important that it has greater support to the program on the part of the Government of the State of the Bahia due the sociocultural relevance and improving the quality of life of the aged ones.
\end{abstract}

Key words: Elderly. Extension. University. UATI.

\section{LA UNIVERSIDAD ABIERTA A LA TERCERA EDAD (UATI) Y LA EXTENSIÓN UNIVERSITARIA: RESIGNANDO LA PRAXIS ACADÉMICA EN LA UNEB CAMPUS XI - SERRINHA}

\section{Resumen}

El aumento de la expectativa de vida en Brasil, a través del crecimiento del número de ancianos, requiere 
cambios en el trato y en la ejecución de políticas públicas del Estado debido al cambio en su perfil. Con el fin de apoyar la promoción de la dignidad humana de aquella parte de la población, motivada por otras instituciones de educación superior, la Universidad del Estado de Bahía (UNEB) creó la Universidad Abierta de la Tercera Edad (UATI), presente en la mayoría de sus campus, sobre todo , en la ciudad de Serrinha, objeto de estudio del presente trabajo, vinculada a la Pro-Rectoría de Extensión (PROEX) - de ahí la necesidad de resignificar la extensión universitaria como praxis académica y sociopolítica por medio de dicho programa. A través del método inductivo de cuño cualitativo, levantamiento histórico / bibliográfico y revisión de literatura acerca de las temáticas, se puede inferir que la UATI es un programa / red de extensión universitaria de conformidad con las normas, planes nacionales, políticas nacionales y el estatuto del anciano , según las actividades desarrolladas. Por fin, para desempeñar mejor sus funciones, es importante que haya un mayor apoyo al programa por parte del Gobierno del Estado de Bahía debido a la relevancia sociocultural a fin de mejorar la calidad de vida de los ancianos.

Palabras claves: Ancianos. Extensión. Universidad. UATI. 


\section{INTRODUÇÃO}

A estrutura etária da população brasileira tem sofrido mudanças significativas nas últimas décadas, a exemplo do aumento de idosos com idade acima de 60 anos que passará dos atuais $10 \%$ para 33,7\% da população total do Brasil segundo o IBGE. Tal mudança vai gerar sérios impactos na previdência social por meio do crescente número de aposentados e pensionistas, acesso às áreas de saúde respeitando o novo perfil dessa parcela da população.

Nesse contexto, emerge a Universidade Aberta à Terceira Idade (UATI), considerada, desde a sua concepção, um programa de educação continuada com ênfase na troca de saberes; de extensão universitária e não formal, visando articular a instituição com essa importante parcela da população - o que justifica a realização do referido trabalho.

Em Serrinha, a UATI, objeto de estudo deste trabalho, pertencente ao Núcleo da Universidade Aberta à Terceira Idade (NUATI), vinculada a Pró-reitora de Extensão (PROEX), da Universidade do Estado da Bahia (UNEB), e possui a missão de atuar junto aos idosos do município promovendo diversas atividades.

Contribui para este trabalho as discussões sobre a extensão universitária mediante a realidade dos idosos no Brasil, analisando os pressupostos teóricos, históricos e jurídicos (Estatuto e Política Nacional do Idoso), como forma de compreender a totalidade da temática a partir dessas especificidades.

Para tanto, tem-se como ponto de partida a seguinte problemática: A organização e a estrutura do Programa Universidade Aberta à Terceira Idade (UATI) atende satisfatória e plenamente as concepções e dispositivos legais sobre extensão universitária, Estatuto e Política do Idoso a partir de uma dada realidade sociocultural, mais especificamente os idosos, no âmbito da UNEB?

Adotou-se ainda, como procedimentos metodológicos, no entendimento de Minayo (et. al., 2000), obra norteadora sobre pesquisas, o seguinte objetivo: Analisar se a organização e a estrutura da UATI correspondem as concepções e instrumentos legais sobre a extensão universitária, o Estatuto e a Política do Idoso, perante a realidade sociocultural, dos idosos, no âmbito daUNEB.

Outro método abordado neste trabalho é o indutivo de cunho qualitativo com base em levantamento histórico/bibliográfico e revisão de literatura. Por isso, defende-se, a viabilidade acadêmica e social deste na certeza de sua contribuição para o debate, o planejamento, a gestão e fortalecimento das ações extensionistas no referido contexto local e regional. 


\section{A EXTENSÃO UNIVERSITÁRIA}

As extensões universitárias, juntamente com o ensino e pesquisa, compõem o trinômio que sustenta as universidades brasileiras, conforme preceitua a Constituição Federal de 1988, no seu Artigo 207 (BRASIL, 1988).

Esse trinômio deve ser regido pelo princípio da indissociabilidade, ou seja, devem estar associados entre si, mas, ela não é recente e sua primeira referência surgiu com o Decreto n. ${ }^{\circ}$ 19.851 de 11/04/1931, conhecida lei Francisco Campos, como forma de elevar a cultura geral do povo afastada da atmosfera universitária.

Outro marco regulatório, dentre outros instrumentos jurídicos e diretrizes expedidos por entidades, é a Lei n. ${ }^{\circ} 4.024$ de 20/12/1961, conhecida como Lei de Diretrizes e Bases da Educação Nacional, cujo Artigo 69, enfrenta críticas quanto o trato a extensão universitária limitando a meros cursos ministrados por docentes e destinados aos membros da própria universidade, enfraquecendo a sua relevância.

Todavia, de acordo com Luckesi, Barreto e Cosma Baptista (1991), espera-se que a universidade cumpra o seu papel de propor uma consciência crítica da sociedade, questionando, investigando, debatendo e discernindo sobre diversas temáticas voltadas as áreas do conhecimento científico, pois

[...] a função de extensão deveria significar a articulação da universidade c om a sociedade, de tal modo que aquilo que ela produz em termos de novos conhecimentos e aquilo que ela difunde através do ensino não ficasse restrito apenas àqueles elementos que conseguem ser aprovados no vestibular e que integram determinado curso objetivando se formar numa determinada profissão. Ao contrário, cabe à universidade socializar seus conhecimentos, difundindo-os à comunidade e se convertendo, assim, numa força viva capaz de elevar o nível cultural geral da sociedade (SAVANI, 1981, p. 73 apud GURGEL, 1986, p. 166).

Eis a definição norteadora da presente discussão, entretanto, verifica-se que a maioria dos projetos registrados no âmbito da universidade limitam a extensão a prática envolve apenas os membros da comunidade acadêmica em detrimento da comunidade externa: lideranças comunitárias, estudantes secundaristas e outros.

Outro paradigma a ser superado na extensão universitária é a concepção de que a relação entre o acadêmico e o público-alvo seja a de superioridade, de dominação, frente aos "leigos" e “inferiores desprovidos de qualquer saber empírico", transformando o público-alvo em coisa e objeto que recebe dócil e passivamente os conteúdos que o outro lhe impõe sendo necessária uma ação transformadora por meio da comunicação ao ser concreto inserindo-o em uma realidade transformadora, conforme Freire (1985). O mesmo autor defende que a extensão "[...] não é outra senão a de estender um 'conhecimento' elaborado aos que ainda não o têm [...]” e nesse 
processo, observado o ponto de vista gnosiológico, “o máximo que se pode fazer é mostrar, sem revelar ou desvelar, aos indivíduos, uma presença nova: a presença dos conteúdos estendidos" (FREIRE, 1985, p. 28).

Nesse contexto, a extensão universitária "não pode ser vista como algo caritativo, mas como uma obrigação, e tem que ser desenvolvida em caráter permanente em atendimento às exigências da classe menos favorecida" (SAVANI, 1981, p. 73 apud GURGEL, 1986, p.167). Isso significa dizer que a extensão não é um ato neutro, isolado e distante da realidade socioeconômica, política e cultural, e sim, um ato político porque deve visar o bem em comum.

Destaca-se, ainda, a Política, o Plano, os Encontros e o Fórum Nacional de Extensão Universitária, que enfatizam a necessidade de mais investimentos, a institucionalização dos programas, o caráter interdisciplinar, educativo, ambiental, cultural, científico e político e a ressignificação do conceito de extensão conforme Rocha (2008), pois:

Queremos, enfim, uma universidade onde possamos lutar para conquistar espaços de liberdade. Enquanto pensamos livremente, questionamos livremente, propomos livremente e livremente avaliamos a nossa responsabilidade (LUCKESI; BARRETO; COSMA BAPTISTA, 1991, p. 44).

Esse caminho pode ser trilhado por meio das contribuições e pressões dos movimentos estudantis em defesa de uma cultura mais popular e nacional contra a elitização burguesa na universidade; do movimento docente em defesa da autonomia universitária, de mais investimentos na extensão e contra a precarização e o produtivismo acadêmico e; o novo protagonismo dos funcionários (técnicos e analistas universitários) por mais abertura de concurso público, maior participação na pesquisa e extensão e na política de valorização e estabilidade horizontal e vertical de acordo com Wanderley (1985).

\section{A questão do idoso no Brasil}

Os idosos, no Brasil e no mundo, compõem a parcela da população que mais cresce em termos demográficos. Esse crescimento traz fortes impactos socioeconômicos a exemplo do aumento de gastos públicos com previdência, assistência social e o Sistema Único de Saúde (SUS), segundo o IBGE.

Tal cenário reflete mudanças sensíveis no perfil do brasileiro onde o idoso, com idade acima de 60 anos ou mais, corresponde a 10,7\% de toda população cuja expectativa de vida ao nascer é de 74,48 anos, segundo o Censo do IBGE 2010.

Em face disso, observa-se a diminuição da taxa de mortalidade entre os idosos (que 
passam a viver mais graças a expectativa de vida e melhores condições socioeconômicas) e fecundidade (diminui-se o número de filhos por cada mulher devido a sua inserção no mercado de trabalho e o aumento de escolarização das mesmas), segundo o mesmoInstituto.

Deve-se levar em conta a intensa atuação dos grupos ligados aos Direitos Humanos no combate às desigualdades socioeconômicas e na garantia de direitos essenciais ao cidadão a exemplo da promulgação da Constituição Federal de 1988, também conhecida como Carta Magna, ou, Constituição Cidadã, devido ao conjunto de princípios e garantias a dignidade e o respeito à pessoa idosa.

Mesmo garantido na Constituição, faz-se necessário regulamentar e disciplinar as políticas públicas e ações de governo a exemplo da Política Nacional do Idoso - Lei n. ${ }^{\circ}$ 8.842/1994.

E para garantir essas conquistas sociais e abarcar a diversidade sociocultural, instituiu-se ainda o Estatuto do Idoso - Lei n. ${ }^{o}$ 10.741/2003. Tal dispositivo é tido como um marco orientando as instituições e as esferas do Estado nas ações destinadas à promoção da dignidade da pessoa idosa.

Apesar desses avanços jurídicos, ainda perdura no Brasil a discriminação, o preconceito e o desrespeito ao idoso que ainda é vítima de diversas formas de violência sendo imperioso efetivar um pacto internacional a exemplo da Carta de São José sobre os direitos dos idosos na América Latina e Caribe; a própria Declaração Universal dos Direitos Humanos que norteia as ações da Organização Mundial das nações Unidas (ONU) e a realização de Conferências Intergovernamentais sobre envelhecimento como forma de refletir as condições atuais .

Dessa forma, as edições de políticas públicas para os idosos são norteadas por tais dispositivos que privilegiam os idosos em sua mais ampla concepção influenciando a destinação de vagas na habitação e moradia; na concepção de lazer e qualidade de vida, na garantia de proteção no âmbito da segurança pública, dentre outros.

\section{A Universidade Aberta à Terceira Idade (UATI)}

A Universidade do Estado da Bahia (UNEB), foi fundada em 1983 e atualmente é estruturada em multicampia, contendo 29 Departamentos em 24 cidades com liderança econômica e política regional na Bahia, vinculada a Secretaria de Educação do Governo do Estado da Bahia, considerada uma das principais responsáveis no fenômeno de interiorização do Ensino Público Superior.

Inspirada no bem sucedido trabalho de outras universidades do país, bem como, no arcabouço jurídico citado acima, a UNEB, em meados de agosto de 1995, tendo como Reitora a Prof $^{a}$ Ivete Alves Sacramento e Pró-Reitor de Extensão o Prof. Lourisvaldo Valentim da Silva, 
criaram o Grupo de Trabalho da Terceira Idade (GTTI), a fim de atender idosos com idade a partir de 60 anos adotando políticas governamentais voltadas a promoção do bem estar do idoso efetivando ações que minimizem os problemas específicos da Terceira Idade.

E no ano de 1997, após crescimento e ampliação do Grupo, passou a se chamar Universidade Aberta à Terceira Idade (UATI), vinculada a Pró-Reitoria de Extensão da UNEB (PROEX), atendendo idosos de ambos os sexos, oriundos dos diversos níveis socioeconômicos e educacionais, objetivando reinserir psicossocialmente os idosos no pleno exercício da cidadania participativa.

Em 2013, na gestão do Reitor Lourisvaldo Valentim da Silva, criou-se o Núcleo da Universidade Aberta à Terceira Idade (NUATI), visando agregar as UATIs instaladas nos Campi da UNEB. Ambas possuem uma coordenação formada por funcionários e/ou professores, a qual, dentre outros objetivos, garante o pleno funcionamento do Programa e conta ainda co m instrutores especializados em diversas áreas do saber e ministra oficinas durante todo o ano e estruturadas em núcleos, a saber:

Quadro 1 - Distribuição das atividades da UATI/UNEB

\begin{tabular}{|c|c|c|}
\hline Núcleo & Objetivo & Oficina \\
\hline Teórico & $\begin{array}{c}\text { Refletir criticamente sobre a realidade } \\
\text { do idoso na Bahia, no Brasil e no } \\
\text { mundo, com base em conceitos sobre } \\
\text { cultura e meio ambiente, fazendo-o } \\
\text { participar da construção da cidadania. }\end{array}$ & $\begin{array}{c}\text { Saúde na Terceira Idade, Alfabetização } \\
\text { de Adultos, Educação para o Consumo, } \\
\text { Identidade e Memória, Nutrição na } \\
\text { Terceira Idade, Meio Ambiente, } \\
\text { Francês, Informática, Psicologia no } \\
\text { Envelhecimento, Para saber o que é } \\
\text { Brasil, Inglês, Tecendo Redes de } \\
\text { Saberes, Espanhol. }\end{array}$ \\
\hline $\begin{array}{c}\text { Vivências } \\
\text { Corporais }\end{array}$ & $\begin{array}{c}\text { Desenvolver a prática de atividades } \\
\text { fícas e de lazer a fim de melhorar as } \\
\text { condições físico-morfológicas, } \\
\text { psicológicas e sociais. }\end{array}$ & $\begin{array}{c}\text { Lazer e Qualidade de Vida, Dança de } \\
\text { Salão, Coral, Dança Flamenca, Dança } \\
\text { Moderna, Rodopiando na Cultura } \\
\text { Popular (Danças Regionais), Yoga, } \\
\text { Expressão Corporal, Tai Chi Chuan, } \\
\text { Dança do Ventre. }\end{array}$ \\
\hline Manuais & $\begin{array}{c}\text { Estimular a autoestima, a } \\
\text { sociabilidade, a criatividade e aguçar } \\
\text { o senso estético e a coordenação } \\
\text { motora. }\end{array}$ & $\begin{array}{c}\text { Artesanato Regional, Embalagem, Mãos } \\
\text { e Criação, Pintura em Gesso e Madeira, } \\
\text { Artes Plásticas, Artes Visuais. }\end{array}$ \\
\hline
\end{tabular}

Fonte: Dados do autor (2016). 
Paralelo ao trabalho acima descrito, o programa realiza ainda palestras, seminários, encontros em parceria com diversos órgãos e instituições, abordando temáticas da atualidade, atividades artístico-culturais e de lazer; intercâmbio com crianças e adolescentes evidenciando a relevância social, o caráter solidário, assim como, entre os estudantes da universidade por meio dos estágios curriculares obrigatórios e projetos de pesquisa e ensino.

Em Serrinha, na década de 1990, no Departamento de Educação da UNEB, Campus XI, um grupo de funcionários já discutia a necessidade de criar um curso de extensão voltado aos idosos. E em meados de 2008, por iniciativa do então Diretor de Departamento, o Prof. Ivan dos Reis Cardoso, estimulou o mesmo grupo a estudar e impla ntar a UATI na cidade, após conhecer as atividades do programa no Campus I-Salvador.

Após um período de adaptação das instalações físicas do Centro de Pesquisas em Culturas e Tecnologias do Território do Sisal (CPCT) (prédio anexo ao Departamento destinados às atividades de pesquisa, extensão e programas especiais) e a inserção de novos funcionários na coordenação, implantou oficialmente a UATI em cerimônia no dia 22 de maio de 2012, conforme Vasconcelos (2012).

Figura 1 - Peça teatral protagonizada pelos idosos - 2013

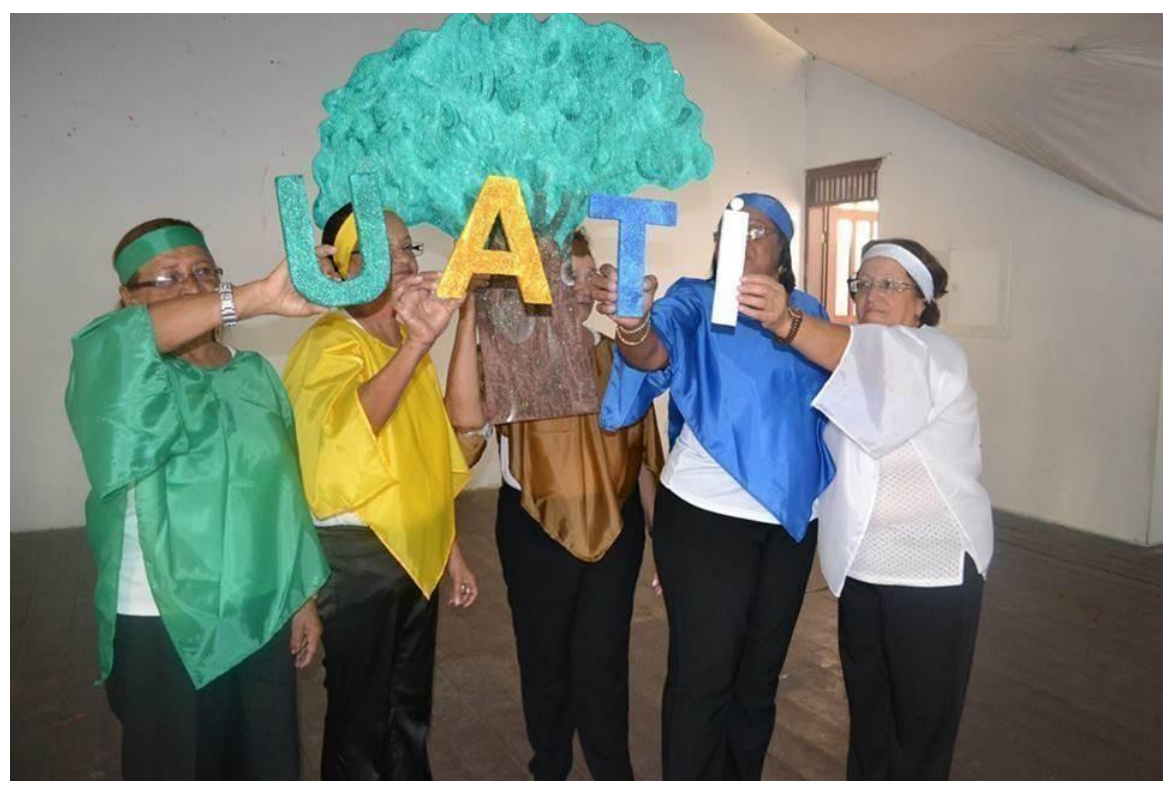

Fonte: www.facebook.com.br/uatiserrinha

Atualmente, a UATI em Serrinha conta com a parceira do Poder Público local, o respaldo do Fórum Permanente em Defesa da Pessoa Idosa da Bahia, do Conselho Municipal da pessoa idosa, Ministério Público da Bahia e demais organismos.

Desde a sua implantação, constatou-se nas observações in loco que os idosos/alunos do 
referido Programa vivenciaram transformações consideráveis e perceptíveis em seus cotidianos a exemplo do aumento da autoestima e motivação para tarefas domésticas; maior conscientização do seu papel no meio em que vivem, além da diminuição de infecções de doenças e internações devido a pressão alta, diabetes, artrite, artrose, dentre outras, graças ao planejamento e execução de oficinas teóricas e de vivências corporais.

Em se tratando de uma extensão universitária, com forte viés de educação continuada porque não estipula prazos para conclusão de turmas e sua estrutura é tida como educação não formal diferenciando-a de escolas regulares, verificou-se que suas oficinas e demais atividades estão devidamente em conformidade com o Estatuto do Idoso, a Política Nacional do Idoso e demais normas que visam a promoção, dignidade, autonomia e participação ativa do idoso na sociedade.

Notou-se ainda que, os intercâmbios entre a UATI e demais entidades com experiências voltadas a Terceira Idade por meio de asilos, as associações, potencializa os saberes dos alunos, sensibilizando a sociedade para as questões inerentes ao desenvolvendo de práticas socioeducativas trabalhando noções de envelhecimento ativo e saudável conforme preceitua o Estatuto do Idoso e a Política Nacional da Pessoa Idosa.

Essas ações coadunam com a Política Nacional de Extensão Universitária que traçou como metas para os próximos anos a melhoria no atendimento a idosos como uma das áreas de atuação prioritárias, na articulação da Extensão Universitária com as políticas públicas - tidas como orientação para todas as universidades no Brasil.

\section{CONSIDERAÇÕES FINAIS}

Tendo em vista sistematizar as observações in loco atrelando-as a discussão teórica e revisão de literatura, apresenta-se neste tópico as considerações sobre a temática a fim de contribuir para o debate.

Apesar de a extensão universitária ser destinadas a comunidade acadêmica e externa, fazse necessário ressignificar o seu papel objetivando combater a banalização da sua práxis como mera formalidade ou procedimento rotineiro que justifique o cumprimento de carga horária.

Isso requer rediscutir as estruturas da universidade renunciando o elitismo acadêmico e egocêntrico tornando-a mais popular e próxima dos verdadeiros valores políticos do bem e m comum na difusão do conhecimento científico e empírico, na liberdade crítica sem perder de vista a defesa pela autonomia universitária. Dessa forma, foi possível constatar que a Universidade Aberta à Terceira Idade (UATI) é uma extensão universitária que não somente 
cumpre o seu papel legal e constitucional, mas, está em conformidade com o direcionamento apontado pelos autores citados neste texto que defendem que as atividades extensionistas, por exemplo, sejam destinadas, preferencialmente as populações menos favorecidas numa perspectiva emancipatória.

A atuação da UATI emerge no processo de valorização e respeito ao idoso na Bahia resinificando o seu papel e fazendo com que a UNEB contribua para o desenvolvimento social e cultural do Estado por meio de sua estrutura multicampi presente nos principais Territórios de Identidade, micro e mesorregiões da Bahia.

Destaca-se ainda o protagonismo dos funcionários Técnicos Administrativos e Analistas Universitários que coordenam e se engajam nas atividades do programa exemplificando um crescente movimento que se espalha em todo o Brasil.

A UATI, por meio de realização das oficinas e demais atividades ministradas durante o ano, está em sintonia com o plano e a política nacional de extensão universitária das universidades públicas, do mesmo modo, em consonância com a Política Nacional da Pessoa Idosa, com o Estatuto do Idoso e a Constituição Federal.

Portanto, necessita-se ainda de maior aproximação e diálogo do Governo do Estado da Bahia com as UATI's visando a subsidiar suas ações firmando parceiras que auxiliem na execução de políticas públicas repassando mais verbas já previstas no Plano Plurianual Participativo, no orçamento anual e outras ações no sentido de atuar sistematicamente em rede promovendo a dignidade humana dessa crescente parcela da população que outrora contribuiu para o crescimento econômico. 


\section{REFERÊNCIAS}

BRASIL. Constituição da República Federativa do Brasil de 1988. Brasília, DF: Casa Civil da Presidência da República, 1988. Disponível em: <http://www.planalto.gov.br/ccivil_03/Constituicao/Constituicao.htm> Acesso em: 29 jul. 2016.

BRASIL. Decreto 19.851/31 de 11 de abril de 1931. Dispõe sobre o estatuto das universidades públicas brasileiras e dá outras providências. Disponível em: <http://www2.camara.leg.br/legin/fed/decret/1930-1939/decreto-19851-11-abril-1931-505837 -publicacaooriginal-1-pe.html> Acesso em: 4 ago. 2016.

Lei n. ${ }^{\circ} 4024$ de 28 de novembro de 1961. Fixa as Diretrizes e Bases da Educação Nacional (LDB). Disponível em: <http://www.planalto.gov.br/ccivil_03/leis/L4024.htm> Acesso em: 04 de ago. 2016.

FÓRUM DE PRÓ-REITORES DE EXTENSÃO DAS INSTITUIÇÕES DE EDUCAÇÃO SUPERIOR PÚBLICAS BRASILEIRAS. Política Nacional de Extensão Universitária. Manaus-AM, Maio 2012. Disponível em:

<https://www.ufmg.br/proex/renex/documentos/2012-07-13-Politica-Nacional-de-Extensao.p df> Acesso em: 4 ago. 2016.

FREIRE, Paulo. Extensão ou Comunicação? 8. ed. Tradução Rosisca Darcy de Oliveira. Rio de Janeiro: Paz e Terra, 1985, 93p.

GURGEL, Roberto Mauro. Extensão universitária: comunicação ou domesticação. São Paulo: Cortez, 1986, p.167.

IBGE - Instituto Brasileiro de Geografia e Estatística. Séries históricas e estatísticas. Disponível em: <http://seriesestatisticas.ibge.gov.br/default.aspx> Acesso em: 2 ago. 2016.

LUCKESI, Cipriano; BARRETO, Elói; COSMA, José; BAPTISTA, Naidison. Fazer Universidade: uma proposta metodológica. 6. ed. São Paulo: Cortez, 1991, 232 p.

MINAYO, Maria Cecília de Souza (Org.); et. al. Pesquisa social: teoria, método e criatividade. 14. ed. Vozes: Petrópolis, 2000, 108p.

ROCHA, José Cláudio Rocha. A reinvenção solidária e participativa da universidade : estudo sobre redes de extensão universitária no Brasil. Salvador: EDUNEB, 2008, 280p.

UNIVERSIDADE DO ESTADO DA BAHIA - UNEB. A Universidade. Disponível em: <http://www.uneb.br/institucional/a-universidade/> Acesso em: 29 jul. 2016.

VASCONCELOS, Toni. Campus de Serrinha festeja inauguração de programa para a terceira idade. Universidade do Estado da Bahia - UNEB. Salvador: 24 de mai. 2012. Disponível em:

<http://www.uneb.br/2012/05/24/autoridades-municipais-prestigiam-inauguracao-da-uati-de-s errinha-250-participam/> Acesso em: 29 jul. 2016. 
WANDERLEY, Luiz Eduardo W. O que é universidade. 5.ed. São Paulo: Brasiliense, 1985, $83 p$.

Cidadania em Ação: Revista de Extensão e Cultura, Florianópolis (SC),v. 2, n. 1, jan./jun. 2018. 